Mesoppotamia J. of Agric.

\title{
INHIBITORY EFFECT OF TANNIC ACID EXTRACTED FROM GRAPE SEEDS AND POMEGRANATE PEELS ON SOME MICROORGANISMS
}

Hamed S.Mohammed Mazin M.I. Al-Zubaidy Majid B.Al-Aswad

Dept. of Food Sci. and Biotech., College of Agric. and Forestry., Univ. of Mosul , Iraq

\begin{abstract}
The study included extraction of tannic acid from grape seeds and pomegranate peels, their content of tannic acid were 4.1 and $27.6 \mathrm{~g} / 100 \mathrm{~g}$ ( dry weight), respectively .The quality tests which done on extracted tannic acid from both sources showed positive results, where the increasing tannic acid concentration leads to increase killing effect on studied microorganisms especially at highest concentration $(2 \%)$.These results showed that extracted tannic acid from both sources can be used as preservation material in food processing and component of cosmetic materials and pharmacological drugs.
\end{abstract}

\section{INTRODUCTION}

Tannins are water soluble polyphenols that present in many different parts of plants(Akiyama et al.,2001), such as Oak tree galls, Peels of banana and pomegranate fruits, fruits of date tree and apple, seeds of coffee and grape as well as in many tropical plants (Huang et al., 1993) .Tannins also play an important role in acceptability of food products and their chemical structures are different, though they have a distinguishing astringent taste (Chung et al.,1998) .Tannins compounds classified into two groups: hydrolyzable tannins, and; non hydrolyzable tannins. The first one is ester of phenolic acids with sugars (Scalbert,1991) .Tannic acid was identified according to Deyeux and Segeux in 1795 (The Birtish Pharmaceutical Codex, 1911). It is Gallotannin which is ester of gallic acid with glucose and then classified as hydrolyzable tannins (Miranda et al., 1996) .Tannins compounds were used in many industrial applications, such as juices clarification and antioxidant material when added to many food products and beverages (Khan et al., 2000), also in oil refining and in preservation of marine meat fish and in manufacture of blue ink (Huang et al., 1993) and a component of cosmetic products and pharmacological drugs due to their activity against chronic dysentery, stimulating healing and treatment cholera and its best antidote against poisonous mushrooms (Chung et al., 1993). Chung et al. (1998) and Scalbert (1991) reported that tannic acid has inhibition effect on many different species of food born bacteria like Aeromonas hydrophila, Escherichia coli, Staphylococcus aureus, Listeria monocytogenes, Salmonella typhi and Enterococcus faecalis. Heil et al. (2002) observed that tannins compounds have inhibition act on some fungi. Many studies had done on extraction of some chemical compounds from plants to identify their quantity, quality properties and inhibition effect on microorganisms (Cowan, 1999), but they didn't take it in consideration to use by products of food processing like pomegranate peels and grape seeds as a source of tannic acid. The main objective of this research is to extract tannic acid from grape seeds and 
pomegranate peels as a by products of local fruits, and determination their quantity, quality properties and inhibitory effect on some microorganisms.

Received 26/10/2007 accepted 14/12/2007

\section{MATERIALS AND METHODS}

1- Samples preparation: The study was done on seeds of local grape fruit (Vitis vinifera var.local) and peels of pomegranate fruit (Punica granatum var.local). Fruit samples were taken from local market of Mosul city, Iraq, cleaned by water, then the grape seeds were extracted by electrical rotary juicer machine, washed by water and scoured by hand to separate tissue and peel of fruits. Pomegranate peels were obtained by removing seeds handly, grape seeds and pomegranate peels were dried separately in drying oven at $55^{\circ} \mathrm{c}$ until their moisture content reached $5 \%$, then milled twice separately to obtain homogenized powder and packaged in vacuum plastic containers, thereafter stored in dark place at $4^{\circ} \mathrm{c}$ until different tests were done ( Heil et al. , 2002) .

2- Tannic acid extraction: Tannic acid was extracted from grape seeds and pomegranate peels according to the procedure of Mole and Waterman ( 1987 ), extraction of tannic acid from grape seeds was modified because of their high content of oil, extraction was done by taking $30 \mathrm{~g}$ of grape seeds powder added to it $200 \mathrm{ml}$ ethanol using soxhlet distillation at $40-60^{\circ} \mathrm{c}$ for 24 hours, the extract was evaporated by using vacuum rotary evaporator to remove solvent, then $100 \mathrm{ml}$ distilled water was added to the residue, oil layer was separated by separation funnel, followed by filtration. Ethyl acetate was added to filtrate many times, later acetate layer was separated and evaporated by using vacuum rotary evaporator until gaining semisolid product (tannic acid) to use it in different tests. Extraction of tannic acid from pomegranate peels was done by taking $20 \mathrm{~g}$ of their powder , and adding 200 $\mathrm{ml}$ distilled water then extracted by soxhlet distillation at $100^{\circ} \mathrm{c}$ for 24 hours, ethyl acetate was added for many times. Acetate layer was separated by separation funnel and evaporated by vacuum rotary evaporator until gaining semisolid product (tannic acid) to use it in different tests.

3- Determination of tannic acid: Tannic acid content of grape seeds and pomegranate peels was determined according to McMurrough and McDowell (1978), by using DMCA (4-Dimethylamino-cinnam aldehyde) reagent .The absorbance was done at $640 \mathrm{~nm}$ by spectronic-20

4- Quality tests: These tests were done to insure that extracted material from grape seeds and pomegranate peels was tannic acid according to The British Pharmaceutical Codex (1911) and Shriner et al. (1964). These tests were included solubility in water, ethanol, ethyl ether, chloroform and benzene and acidity test with litmus paper and formation white crude with gelatin or albumin and formation colored precipitate with potassium chromate, lead or cupper acetate, ferric chloride, potassium cyanide and purity test when treated with calcium chloride to distinguish tannic acid from gallic acid.

5- Microbiological tests: Tested strains: Different microbial strains were chose according to their role in food processing. Some of these microbial strains caused undesirable effect and food deterioration ,such as, gram positive or negative bacteria, different optimum growth temperature, spore former, or non spore former bacteria and different shapes of bacteria. The studied microorganisms, included: 
1. Bacillus subtilis, Staphylococcus aureus, Escherichia coli, Lactobacillus bulgaricus ( L.delbruekii sub sp. bulgaricus) and Streptococcus thermophilus ( Str. salivarius sub sp. thermophilus ).

2. Saccharomyces cerevisiae and Aspergillus niger.

The pure cultures were obtained from the Department of Food Science and Biotechnology, College of Agriculture and Forestry, Mosul University. The media that used for the growth of microorganisms were milk starch agar ,mannitol salt agar, macconkey agar ,MRS agar and potato dextrose agar .These media were prepared according to Harrigan and MacCance ( 1976 ) and Diliello(1982), the microbial cultures were activated at $37^{\circ} \mathrm{c}$ for 24 hours before test by using nutrient broth for Bacillus subtilis, macconkey broth for E. coli, nutrient broth and skim milk for lactic acid bacteria, brain heart infusion for Staph. aureus_and malt broth for fungi which incubated at $28^{\circ} \mathrm{c}$ for 4 days .The suitable dilution of activated microorganisms were prepared by using physiological solution ( distilled water $+0.1 \%$ peptone in test tubes which contained $9 \mathrm{ml}$,by using dilution $10^{-4}, 10^{-5}, 10^{-6}$ ). The concentrations of tannic acid that added to nutrient media were $0.5,1.0,1.5$ and $2.0 \%$. To study the resistance of studied microorganisms was done by putting $1 \mathrm{ml}$ of each dilution in two replicate and putting it in sterilized petri dish that contained sterilized nutrient agar media and tannic acid, mixed together with cyclic motion ,then lefted until the media sold then incubated at $37^{\circ} \mathrm{C}$ for 3 days for bacteria and 5 days at $28^{\circ} \mathrm{C}$ for fungi .

The growing colonies number were determined and multiplied by dilution reciprocal to obtain total numbers of studied microorganisms .\% of reduction ratio of studied microorganisms was determined by using this equation:

No. of microorganisms without tannic acid- No. of microorganisms with tannic acid

$=\frac{\text { No. of microorganisms without tannic acid }}{} \times 100$

\section{RESULTS AND DISCUSSION}

1- Tannic acid content: Table (1) reveals that the tannic acid content of grape seeds is $4.1 \mathrm{~g} / 100 \mathrm{~g}$ (dry weight), which is less than what Hulme (1971) reported where the content of total tannin was $4.5 \mathrm{~g} / 100 \mathrm{~g}$, and higher than what Rabak and Shrader (1981) found in that the content of tannic acid was $1.55 \%$. This variation can be explained on the differences between studied species of grape fruits, genetic factorial, extraction method, season of taking samples and breeding circumstances which have a significant effect on chemical constitutes of fruit. The ratio of seeds to grape fruit was between 3 $-4 \%$, therefore the amount of tannic acid from $1000 \mathrm{~g}$ fruit was between 120 - $160 \mathrm{~g}$ which is a little amount comparing with the result mentioned by Dalaly and Al-Hakim (1987) which indicated that total tannin content of tea leaves was between 7-15\% (wet weight) and between $30-70 \%$ of tannic acid in Oak tree galls ( Mohammed et al., 1988), thus, grape seeds is not considered as an important source of tannic acid. The result in the same table shows that the tannic acid content of pomegranate peels is $27.6 \mathrm{~g} / 100 \mathrm{~g}$ ( dry weight ), this result is higher than the findings of Dalaly and Al- Hakim (1987 
) which showed that total tannin content of pomegranate peels was $20 \%$

\begin{tabular}{|c|c|c|}
\hline \multirow{3}{*}{ Quality tests } & \multicolumn{2}{|c|}{ Tannic acid content (dry weight ) } \\
\hline & Grape seeds & Pomegranate peels \\
\hline & $4.1 \mathrm{~g} / 100 \mathrm{~g}$ & $27.6 \mathrm{~g} / 100 \mathrm{~g}$ \\
\hline 1.Solubility & & \\
\hline a-water & + & + \\
\hline b-ethanol & + & + \\
\hline c-chloroform & - & - \\
\hline d-benzene & - & - \\
\hline $\begin{array}{l}\text { 2-Acidity } \\
\text { Litmus paper indicator }\end{array}$ & red & red \\
\hline $\begin{array}{l}\text { 3-Colored precipitate } \\
\text { a-ferric chloride } \\
\text { b-potassium cyanide } \\
\text { c-potassium chromate } \\
\text { d-lead acetate } \\
\text { e-cupper acetate }\end{array}$ & $\begin{array}{l}\text { blue } \\
\text { blue } \\
\text { brown } \\
\text { brown } \\
\text { brown }\end{array}$ & $\begin{array}{l}\text { blue } \\
\text { blue } \\
\text { brown } \\
\text { brown } \\
\text { brown }\end{array}$ \\
\hline $\begin{array}{l}\text { 4-Crude test } \\
\text { a-gelatin } \\
\text { b-albumin }\end{array}$ & $\begin{array}{l}+ \\
+ \\
\end{array}$ & $\begin{array}{l}+ \\
+ \\
\end{array}$ \\
\hline $\begin{array}{l}\text { 5-purity test } \\
\text { calcium chloride }\end{array}$ & pink & pink \\
\hline
\end{tabular}

.Accordingly, it was concluded that pomegranate peels are important source of tannic acid comparing with grape seeds .

2 - Quality tests: All quality tests that done on extracted material from grape seeds or pomegranate peels gave positive results, which indicate that the extracted material from both sources is tannic acid. The extracted material gave total solubility in water (1 part : 1 part) and with ethanol ( 10 parts : 1part ) and insoluble in ethyl ether or in chlorophorm or in benzene and produced red

Table ( 1 ): Quality tests and tannic acid content of grape seeds and pomegranate peels + : Positive result ؛ $\quad$ :Negative resul

color with litmus paper (acidity test) while formed blue precipitate with ferric chloride or with potassium cyanide and produced brown precipitate with potassium chromate or with lead or cupper acetate and produced pink color with calcium chloride to insure that the extracted material was pure and neither hydrolyzed nor contaminated. These results agreed with the British Pharmaceutical Codex (1911) and Schmidt (1956) and Shriner et al . (1964).

3 -Inhibition effect on microorganisms: Results in figure (1) showed that increasing tannic acid concentration caused decreasing in bacterial numbers and increasing reduction ratio .The Staph. aureus is the most sensitive bacteria to tannic acid especially at $2 \%$.It's initial number was $13 \times 10^{5}$ decreased to $4 \times 10^{5}$ c.f.u $/ \mathrm{ml}$, and the reduction ratio was $69 \%$.The initial number of E.coli was $33 \times 10^{4}$ then decreased to $16 \times 10^{4}$ c.f.u $/ \mathrm{ml}$, and the reduction ratio was $51 \%$ ,and Bacillus subtilus with its initial number $68 \times 10^{6}$ decreased to $47 \times 10^{6}$ spores $/ \mathrm{ml}$, and the reduction ratio which was $30 \%$ is lesser sensitive . 
Mesoppotamia J. of Agric.

Figure ( 2 ) showed that the effect of tannic acid concentrations on numbers of Str.thermophilus ( Str. salivarius sub sp. thermophilus) and Lact. bulgaricus (L. delbruekii sub sp. bulgaricus ) .Using $2 \%$ of extracted tannic acid caused decreasing initial numbers of Str. thermophilus_from $52 \times 10^{4}$ to $26 \times 10^{4}$ c.f.u $/ \mathrm{ml}$, the reduction ratio was $50 \%$.The initial number of Lact . bulgaricus was decreased from $3 \times 10^{4}$ to $16 \times 10^{3}$ c.f.u/ $\mathrm{ml}$, the reduction ratio was $46 \%$. 


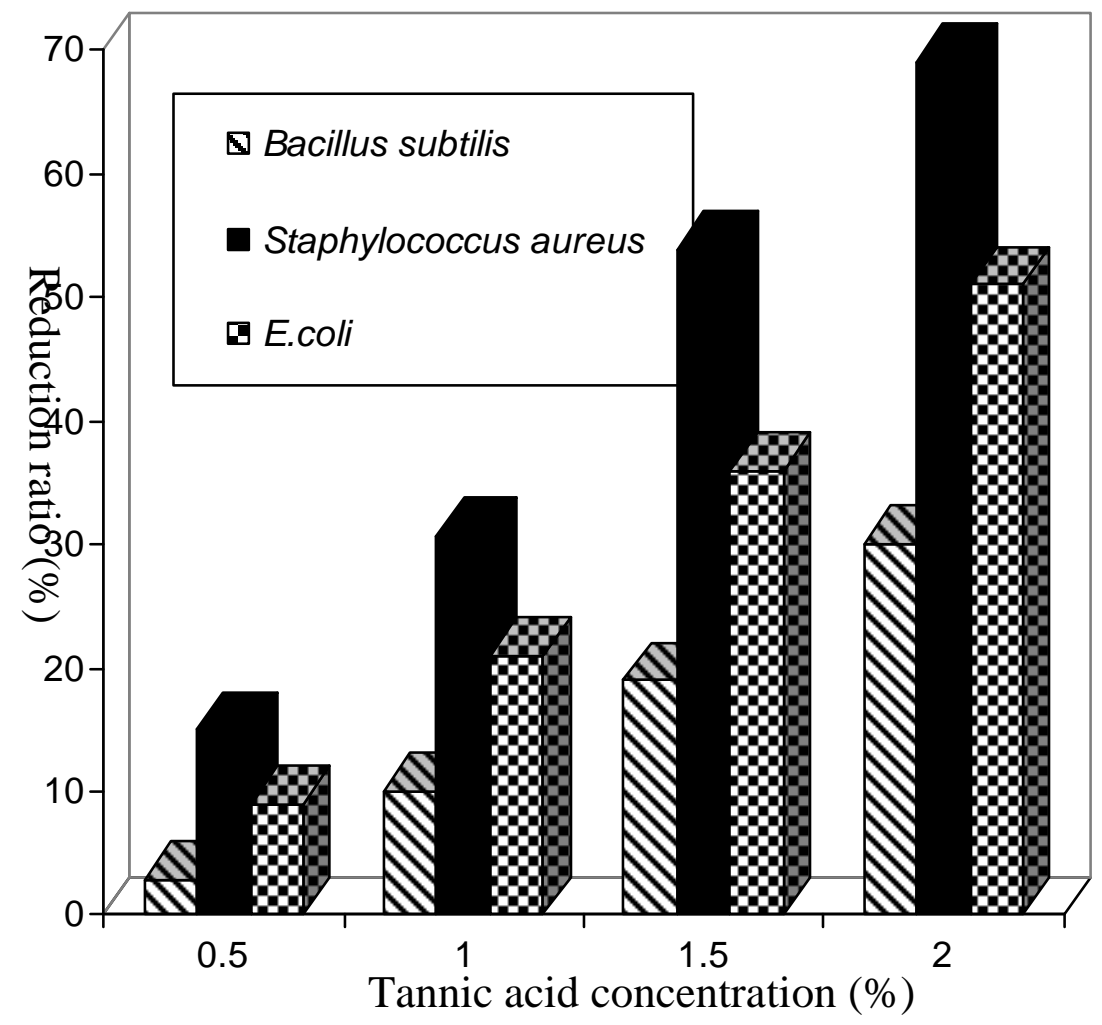

Figure (1): Effect of different tannic acid concentrations on number of Bacillus subtillis,

Staphylococcus aureus and E.coli

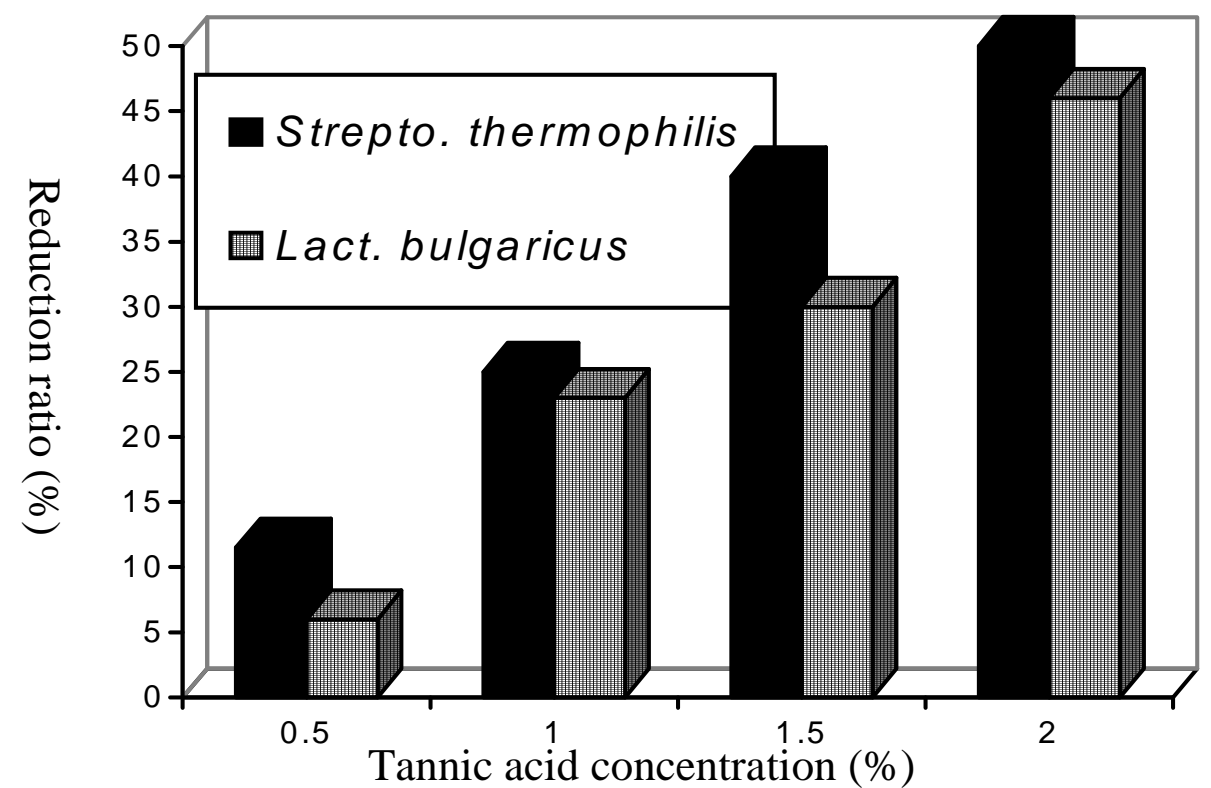

Figure (2): Effect of different tannic acid concentrations on number of Streptothermophilis and Lact. Bulgaricus

Figure ( 3 )showed that using 2\% tannic acid caused highly effect on numbers of studied fungi, where decreased the initial numbers of Aspergillus 
niger from $46 \times 10^{5}$ to $38 \times 10^{5}$ c.f.u $/ \mathrm{ml}$. The reduction ratio was $17 \%$, and caused decreasing

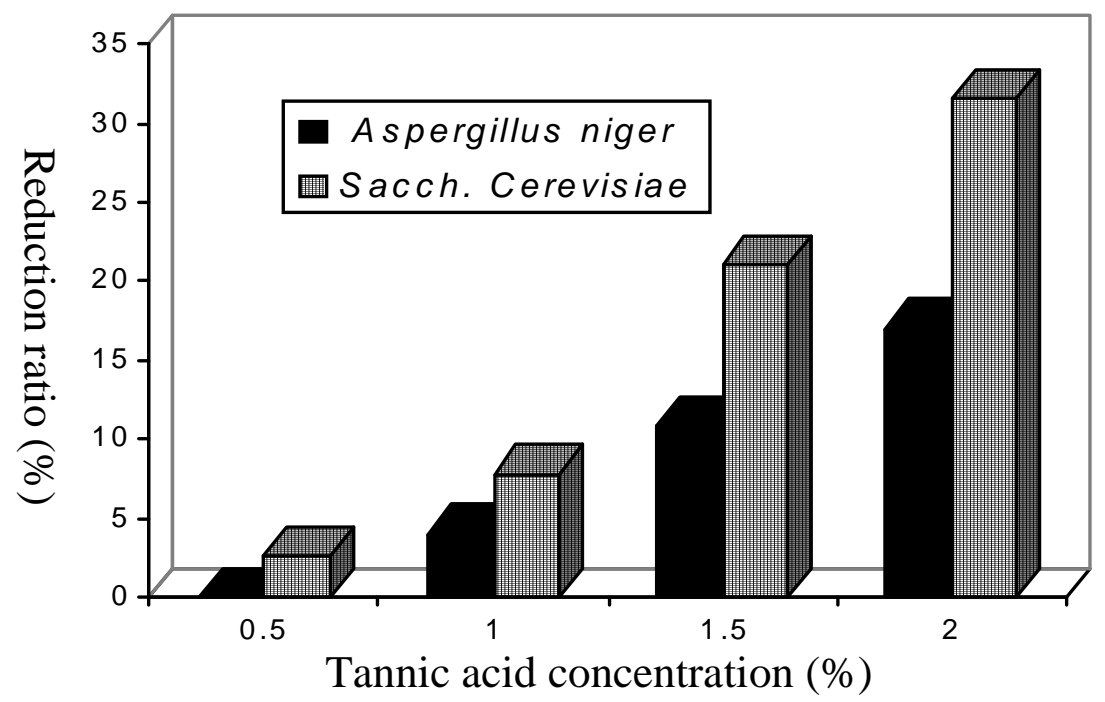

Figure (3): Effect of different tannic acid concentrations on number of Aspergillus niger and Sacch. cerevisiae

initial numbers of Saccharomyces cerevisiae from $38 \times 10^{4}$ to $26 \times 10^{4}$ c.f.u $/ \mathrm{ml}$, the reduction ratio was $31.5 \%$.

It was concluded from these results that the most resistant bacteria to tannic acid is Bacillus subtilis , because of their content of hard wall spores and low moisture content in addition to their content of dipicolinic acid which binding with calcium ions. This agrees with Chung et al. (1998).

These results indicated that the most microorganisms resistance to tannic acid is Aspergillus niger and Saccharomyces cerevisiae and this due to their complex chemical structure of their walls comparing with the structure of bacteria walls ( Saleh and Bassam, 1982 ). It was observed from figure 1, 2,3 that the most effective concentration of tannic acid is $2 \%$ . This caused reduction in number of Staph. aureus, E. coli, Str.thermophilus ,Lact. bulgaricus , B. subtilis Saccharomyces cerevisiae and Aspergillus niger in ratio 69,51,50,46,30,17 and $31.5 \%$, respectively. These results agree with Scalbort (1991) who had observed that tannic acid inhibited the oxidative phosphorylation pathway and microbial enzyme which hydrolyse the substrate that needs during growth such as proteolytic, lipolytic enzymes and carbohydratase and observed its binding with proteins by formation polymer compounds with hydroxyl groups. 


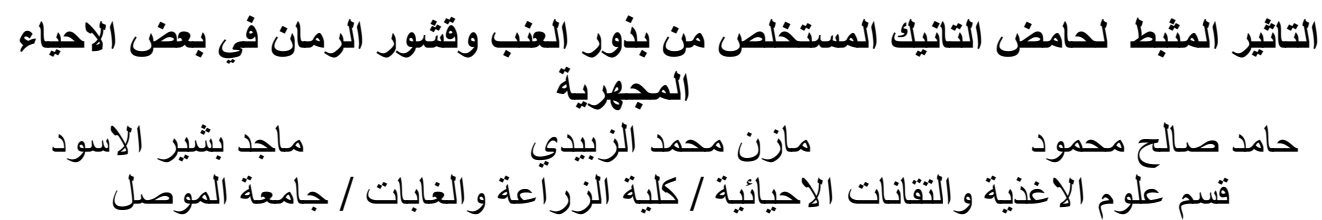

\section{الخلاصة}

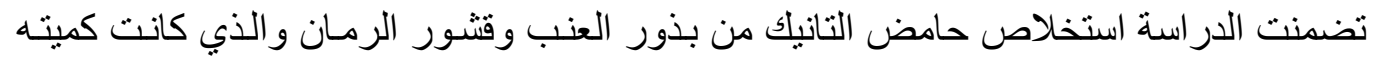

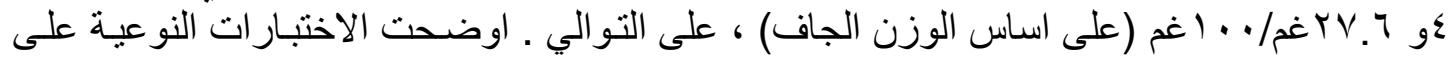

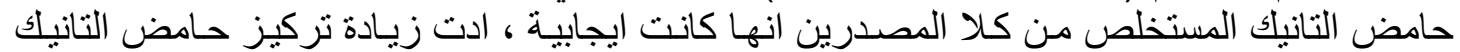

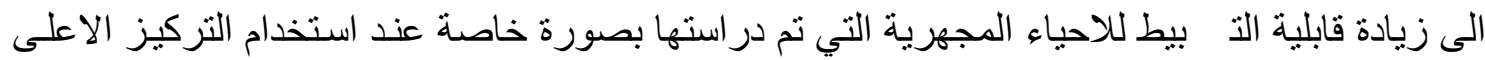

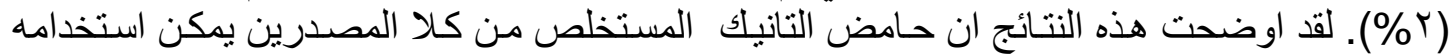

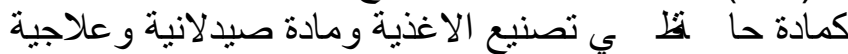

\section{REFERENCES}

Akiyama, H. , Fujii , K. , Yamascki , O., Oono ,T. and Iwatsuki ,T ( 2001 ) . Antibacterial action of several tannins against Staph. aureus . J .of Antimicrobial Chemotherapy , $48: 487-491$.

Chung,K., Stevens , S.,Lin ,W.and Wei,C.(1993 ).Growth inhibition of selected food born bacteria by tannic acid ,propylgallate and related compounds . Letters in Applied Microbiology , 17:29-32.

Chung, K. , Wong, T. ,Wei , T. and Huang , Y. (1998) . Tannins and human health . Critical Reviews in Food Science and Nutrition , 38 :421464 .

Cowan , M.(1999).Plant products as antimicrobial agents. Clinical Microbiology Reviews ,12:564-582.

Dalaly ,B.and Al-Hakim, S. ( 1987) . Food Analysis .Books House for Printing and Publishing, Mousl University, Iraq (in Arabic) .

Diliello, R. ( 1982 ). Methods in Foods and Dairy Microbiology . West Port , CT:AVI Pub.Co

Harrigan ,W. and MacCance , M. (1976 ) .Laboratory Methods in Food and Dairy Microbiology . Academic press . Inc. New York .

Heil , M.,Baumann ,Andary,C. , Edward ,K.and Mckey , D.(2002 ). Extraction and quantification of condensed tannins . Naturwissenschaften , 89 : 519-524

Huang, Y. , Low , L. ,Chung, K.and Huang , C. (1993) . Effect of tannic acid, gallic acid and propyl gallate on storage life of cat fish ,Proceeding :Tropical and Subtropical Fishers Technological Conference of the Americans . University of Florida , 324-239.

Hulme , I.(1971).The Biochemistry of Fruit and Fruit Products(vol.2) .Academic press , New York .

Khan , N. , Ahmed, A.and Hadi , S. (2000). Antioxidant , Prooxidant properties of tannic acid and it's binding to DNA, Chem . Biol . Interact ,125:

McMurrough , I. and McDowell , J. ( 1978 ) . Chromatographic separation and automated analysis of flavanols . Analytical Biochemistry , 91:92-100.

Miranda , C., Wyk, C.,Bijl , . C.and Basson W. (1996) . The effect of areca nut selected on microorganisms . International Dentel J. 46: 350-356.

Mohammed , A., Amim , A., AlHamadani , R. and Ahmad , B. ( 1988 ). Morphological and chemical study of different galls produced by gall 
wasps on oak trees in northen Iraq . Arab J.Plant protection ,6:76-78(in Arabic).

Mole , S. and Waterman , P. ( 1987 ). A critical analysis of techniques for measuring tannins. Oecologica, $72: 148-156$.

Raback , F.and Shrader , J. (1981).Commercial utilization of grape pomace and stems. U.S.Dept.Agric.Bull,952.

Saleh , K. and Bassam, T. ( 1982 ). Food Microbiology , Books House for Printing and Publishing ,Mousl University .Iraq (in Arabic).

Scalbert , A.( 1991 ). Antimicrobial properties of tannins . Phytochemistry, 30:3875-3883.

Schmidit ,O. ( 1956 ) Fortoshr .chem .org .Naturst. ,13:70.

Shriner , R.Fuson ,R.and Curtin D.(1964) . Systematic identification of organic compounds $\left(5^{\text {th }}\right.$ ed $)$, John Wiley and Sons Ltd.

The British Pharmaceutical Codex (1911) .Acidum Tannicum. 